\title{
NUMERICAL SIMULATION OF HEAVY OIL RECOVERY BY STEAM-ASSISTED GRAVITY DRAINAGE METHOD
}

\author{
ANASTASIIA A. KOSTINA ${ }^{1}$, MAXIM S. ZHELNIN² AND OLEG A. PLEKHOV ${ }^{3}$ \\ ${ }^{1}$ Institute of continuous media mechanics of the Ural branch of Russian academy of science \\ 614013, Ac. Koroleva st.,1, Perm, Russia \\ kostina@icmm, http://www.icmm.ru/index.html \\ ${ }^{2}$ Institute of continuous media mechanics of the Ural branch of Russian academy of science \\ 614013, Ac. Koroleva st.,1, Perm, Russia \\ zhelnin.m@icmm, http://www.icmm.ru/index.html \\ ${ }^{3}$ Institute of continuous media mechanics of the Ural branch of Russian academy of science \\ 614013, Ac. Koroleva st.,1, Perm, Russia \\ poa@icmm, http://www.icmm.ru/index.html
}

Key words: SAGD, FEM, Coupled Problems, Multiphase Flow.

Abstract. Steam-assisted gravity drainage method (SAGD) is an efficient technique for a heavy oil recovery which is characterized by values of recovery factor up to 0.8 . This work is devoted to the three-dimensional field-scale numerical simulation of SAGD taking into account various kind of non-uniformity induced by technological reasons as well as heterogeneous structure of the reservoir. The proposed coupled thermo-hydro-mechanical model includes conservation laws of momentum, mass and energy which are supplemented by constitutive equations and state laws. Results have shown that oil production rate is significantly affected by the presence of the barrier layers as well as non-uniformity of the steam propagation along the horizontal wellbore.

\section{INTRODUCTION}

Natural depletion of conventional oil resources leads to development of new technologies applicable to heavy oil recovery. Thermal methods are approved to be very efficient in viscous oil production. Worldwide experience has shown that steam-assisted gravity drainage (SAGD) can be successfully applied to crude oil recovery especially in reservoirs with vertical permeability more than $1 \mathrm{D}$ [1]. In this case recovery factors have values of 0.7-0.8 which are almost two times greater in comparison with cyclic steam stimulation [1].

According to SAGD, a number of horizontal well-pairs are drilled one above the other at the distance of 70-100 m. On the initial stage steam is injected through both wells to establish inter-well communication. On the next stage steam is injected only through upper well leading to formation of a steam-saturated zone which is called steam chamber. There are three stages in steam chamber development: vertical rise to the upper boundary of the reservoir, lateral spreading along the upper boundary up to the coalescence with neighbouring steam chamber and downward expansion to the bottom [2]. Along with the heating, steam chamber development induces condensation of steam during interaction with a cold part of the 
reservoir. Hot temperature reduces oil viscosity and oil together with a condensed steam flow down the edge of the steam chamber into the production well due to the gravity.

Analytical models of SAGD [3-5] are widely applied for evaluation of oil recover rate. However, these models often neglect some important effects which are upward rise of the steam chamber, convection, pressure gradient induced by the gravity and heterogeneity of the reservoir. More accurate solution requires numerical simulation [6-8] which accounts for these effects and specific features of the considered reservoir.

As it has been mentioned by S. Huang et al. [9] steam chamber in oilfield conditions commonly has non-uniform distribution along the horizontal wellbore because of wellbore flow resistance, steam characteristics, steam injection rate, pressure drop and so on. In addition, oil reservoirs can have non-uniform structure due to the presence of the impermeable shale barrier layers which also affect steam chamber shape [10]. Therefore, to obtain accurate prediction of oil rate in the specific reservoir it is necessary to develop threedimensional numerical models which account for steam-chamber non-uniformity induced by technological factors and heterogeneous structure of the reservoir.

Commonly, thermo-hydro-mechanical simulation of SAGD is carried out using sequential coupling approaches. In this case, thermal and filtration problems are solved in one software (PumaFlow, STARS) and geomechanical problem is solved in another (ABAQUS, FLAC2D). Fully coupled approach doesn't require data transfer between two different simulators because solution of the problem is carried out in one software. It enables more accurate description of stress-strain state evolution and its effect on reservoir properties. This work is dedicated to three-dimensional numerical simulation of SAGP in a fully-coupled manner using finite-element mechanisms of SAGL convective heat transfer reservoir properties. Moreover, proposed thre-dimensional scale numerical simulation, study effects of impermeable barrier layers and non-uniform

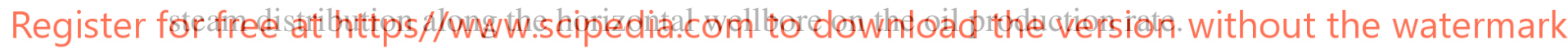

\section{MATHEMATICAL MODEL OF SAGD}

Reservoir is considered as porous media filled with three-phase flow which consists of steam, oil and water. Phases are assumed to be non-miscible. Capillary pressure is smaller than pressure drop induced by the gravity, therefore its effect is neglected. Phase transition in the considered porous media is induced by the temperature change only. Mathematical model includes mass, energy and momentum conservation laws which are supplemented by Darcy's law for each phase, constitutive equations of Biot poroelastic theory and additional equations relating reservoir properties to volumetric strain.

\subsection{Three-phase flow in porous media}

Three-phase flow in porous media is described by mass balance equations and Darcy's laws for each pahse. Mass conservation laws have the following form:

$$
\frac{\partial\left(n \rho_{s} S_{s}\right)}{\partial t}+\bar{\nabla} \cdot\left(\rho_{s} \bar{v}_{s}\right)=q_{s}
$$




$$
\begin{gathered}
\frac{\partial\left(n \rho_{w} S_{w}\right)}{\partial t}+\bar{\nabla} \cdot\left(\rho_{w} \bar{v}_{w}\right)=q_{w}, \\
\frac{\partial\left(n \rho_{o} S_{o}\right)}{\partial t}+\bar{\nabla} \cdot\left(\rho_{o} \bar{v}_{o}\right)=0,
\end{gathered}
$$

where subscripts $s, w, o$ denote steam, water and oil phase respectively; $n$ is the porosity; $\rho_{i}$, $(i=s, w, o)$ is the density; $S_{i}(i=s, w, o)$ is the relative saturation; $t$ is the time, $\bar{v}_{i}(i=s, w, o)$ is the phase velocity; $q_{i}(i=s, w)$ is the mass source induced by steam condensation.

Mass sources $q_{s}$ and $q_{w}$ is defined similar to the model proposed in [11]:

$$
q_{s}=-q_{w}=r n S_{s} \rho_{s} \frac{T-T_{s a t}}{T_{s a t}}, T \leq T_{s a t},
$$

where $r$ is the mass transfer intensity factor; $T$ is the temperature; $T_{\text {sat }}$ is the phase transition temperature.

Phase velocities with accounting for gravity are described by Darcy’s law:

$$
\bar{v}_{s}=-\frac{K k_{r s}}{\mu_{s}}\left(\bar{\nabla} p-\rho_{s} \bar{g}\right),
$$
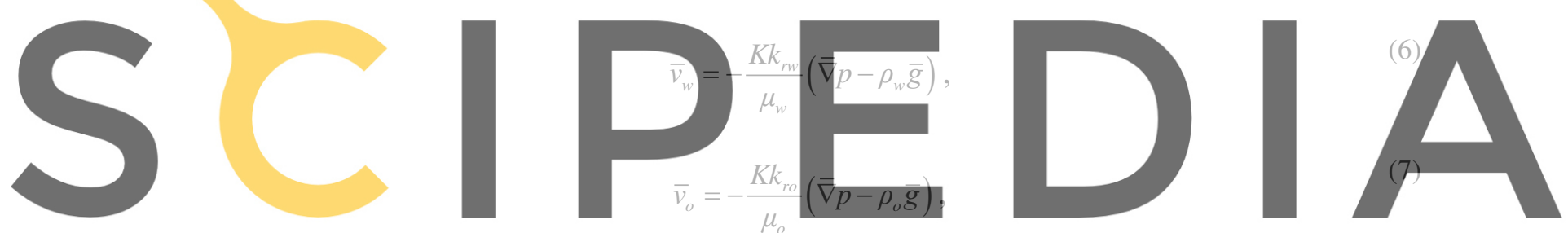

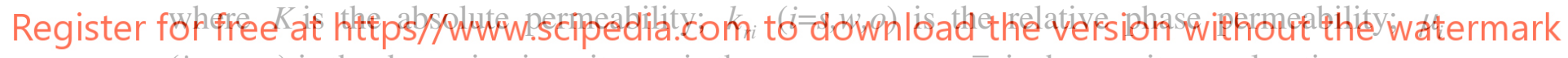

$(i=S, W, O)$ is the dynamic viscosity; $p$ is the pore pressure; $\bar{g}$ is the gravity acceleration.

Equations (1)-(7) are supplemented by the condition of a fully saturated media:

$$
S_{w}+S_{o}+S_{s}=1 \text {. }
$$

\subsection{Energy balance equation}

Energy conservation law for a three-phase flow in porous media with accounting for convective heat transfer and latent heat induced by steam condensation can be written as

$$
\frac{\partial}{\partial t}\left\{T\left[(1-n) \rho_{r} c_{r}+n \sum_{i=w, o, s} \rho_{i} S_{i} c_{i}\right]\right\}+\bar{\nabla} \cdot\left(-\lambda_{e f f} \bar{\nabla} T\right)+\bar{\nabla} \cdot \sum_{i=w, o, s} \bar{v}_{i}\left(\rho_{i} c_{i} T\right)=Q .
$$

where subscript $r$ refers to properties of the reservoir; $\rho_{r}$ is the density of solid skeleton; $c_{i}$ $(i=s, w, o, r)$ is the heat capacity; $\lambda_{\text {eff }}=\sum_{i=w, o, s} n S_{i} \lambda_{i}+(1-n) \lambda_{r}$ is the effective conductivity; $Q=L q_{s}$ is the heat source induced by steam condensation; $L$ is the latent heat. 


\subsection{Equilibrium equation and constitutive relations}

Equilibrium equation with account for gravity has the following form

$$
\nabla \cdot \tilde{\sigma}+\rho_{e f f} \bar{g}=\overline{0},
$$

where $\tilde{\sigma}$ is the total stress tensor; $\rho_{\text {eff }}=\sum_{i=s, w, o} n S_{i} \rho_{i}+(1-n) \rho_{r}$ is the effective density.

Total strain tensor $\tilde{\varepsilon}$ is calculated as

$$
\tilde{\varepsilon}=1 / 2\left(\nabla \bar{u}+\nabla \bar{u}^{T}\right),
$$

where $\bar{u}$ is the displacement vector.

Usually, SAGD is applied to reservoirs with low value of overburden pressure. Therefore, constitutive equation of Biot theory of poroelasticity is used as a first approximation:

$$
\tilde{\sigma}=\lambda I_{1} \tilde{E}+2 \mu \tilde{\varepsilon}^{e}-\alpha_{B} p \tilde{E},
$$

\section{where $\lambda=2 v E /(1+v)(1-2 v), \mu=E / 2(1+v)$ are Lame parameters; $E$ is Young's modulus; $v$}

is Poisson's ratio; $I_{1}$ is the first invariant of elastic strain tensor; $\widetilde{\varepsilon}^{e}$ is elastic strain tensor; $\tilde{E}$ is the unit tensor; $\alpha_{B}$ is the Biot coefficient.

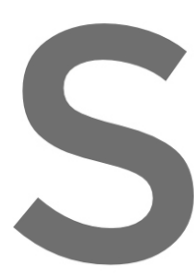

Total strain tensor
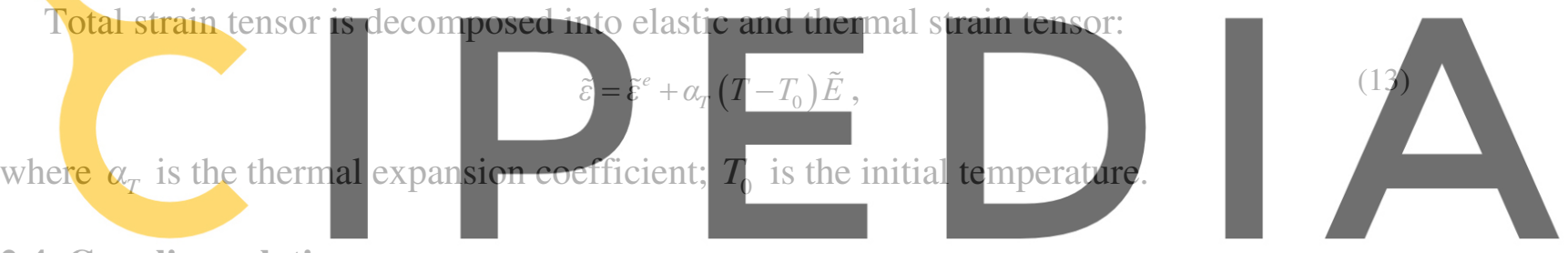

2.4 Coupling relations

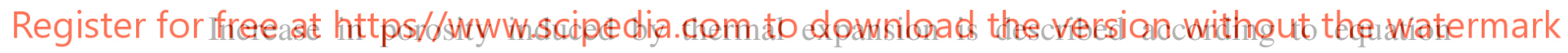

proposed in [12]:

$$
n=\frac{n_{0}+\varepsilon_{v o l}}{1+\varepsilon_{v o l}}
$$

where $n_{0}$ is the initial porosity; $\varepsilon_{v o l}$ is the volumetric strains.

Absolute permeability of the reservoir is related to the porosity as [13]:

$$
K=d \frac{n^{3}}{(1-n)^{2}},
$$

where $d=K_{0}\left(1-n_{0}\right)^{2} / n_{0}^{3}$ ensures that initial value of absolute permeability is equal to $K_{0}$.

\subsection{Initial and boundary conditions}

Initial pore pressure distribution corresponds to the equilibrium state given by the gravity

$$
p(t=0)=p_{u p}+\rho_{o} g\left(z_{u p}-z\right),
$$


where $p_{u p}$ is the overburden pressure; $z_{u p}$ is the thickness of the reservoir; $z$ is the vertical coordinate.

Initial conditions with regard to the temperature, steam saturation, water saturation and displacements are the following

$$
\begin{gathered}
T(t=0)=T_{0}, \\
S_{s}(t=0)=0, \\
S_{w}(t=0)=1-S_{o}^{0}, \\
\bar{u}(t=0)=\overline{0},
\end{gathered}
$$

where $S_{0}^{0}$ is the initial oil saturation.

In addition to (16)-(20), initial stress distribution induced by the gravity is given.

On the injection well boundary the following conditions are applied

$$
\left.p\right|_{\Gamma_{i}}=p_{b},
$$
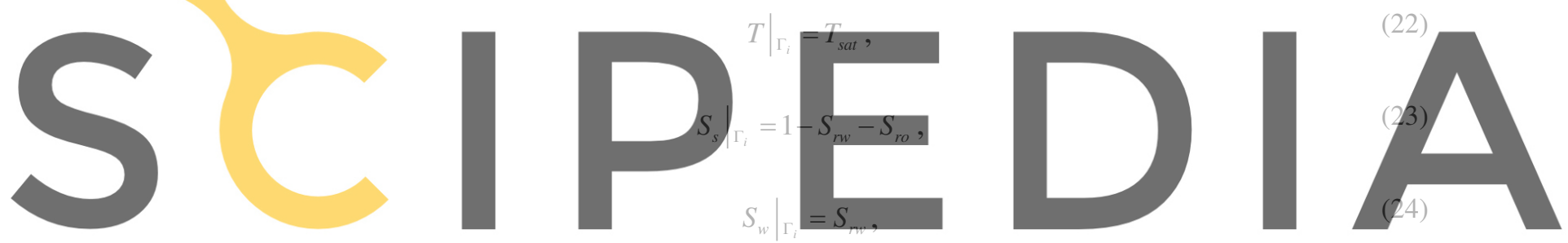

Register for free at https//www.scipedia.com ${ }_{u_{x}} \phi_{1}$ download the version without the (Aratermark

$$
\left.u_{y}\right|_{\Gamma_{i}}=0
$$

where $\Gamma_{i}$ is the injection well boundary; $p_{b}$ is the pressure of the injected steam; $S_{r w}$ is the residual water saturation; $S_{r o}$ is the residual oil saturation; $u_{x}$ is horizontal displacement; $u_{y}$ is longitudinal displacement.

Outflow boundary condition is given on the production well boundary for steam and water saturations as well as thermal insulation for temperature and constant pore pressure value. No flow condition is applied on other boundaries for steam saturation, water saturation and pore pressure. Horizontal displacements are suppressed on right and left boundaries and longitudinal displacements are disabled on front and rear surfaces. All components of displacement vector is equal to zero at the lower boundary of the reservoir. 


\section{FIELD-SCALE NUMERICAL SIMULATION}

Numerical simulation was carried out in a finite-element software Comsol Multiphysics. Solution of three-phase flow problem was based on pressure-saturation formulation with total velocity. Equations (1)-(8) were reformulated for the unknowing variables of steam saturation, water saturation, pressure and represented in a weak form. Artificial diffusion term was added to smooth oscillations induced by convective terms. The obtained equations were solved by Weak Form PDE Interface. Equation (9) was solved relative to the temperature by Heat Transfer in Porous Media Interface. Solid Mechanics Interface was applied for solution of (10)-(13). Proposed algorithm enables to solve non-linear multiphysics problem (1)-(15) in a fully coupled manner using one software.

\subsection{Effect of barrier layers}

As it has been mentioned in the introduction, oil reservoirs often have non-uniform structure due to the presence of the impermeable shale barrier layers. Therefore, this effect should be taken into account to obtain accurate prediction of the oil rate.

This example considers propagation of the steam chamber in the reservoir with several barrier layers. The developed model (1)-(26) was applied to the numerical simulation of reservoir's area containing two pairs of SAGD wells. The reservoir properties correspond to Yarega oil deposit (Russian heavy oil deposit in Komi Republic). The reservoir has a height of $19 \mathrm{~m}$, a length of $70 \mathrm{~m}$ and a width of $0.004 \mathrm{~m}$. Distance between bottom of the reservoir and production well is $8 \mathrm{~m}$. The wells have a radius of $0.178 \mathrm{~m}$, distance between them is equal to $5 \mathrm{~m}$. Temperature and pressure of the injected steam are respectively. The time of

Firstly, we consider evolution of temperature stages of steam chamber development: upward rising stage (Fig.1 (a)), lateral spreading stage

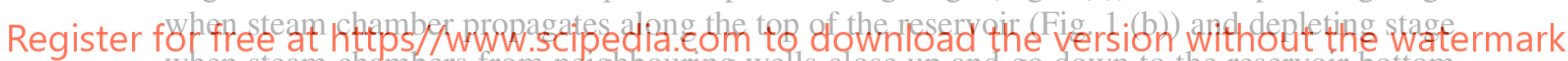
when steam chambers from neighbouring wells close up and go down to the reservoir bottom (Fig. 1 (c)).

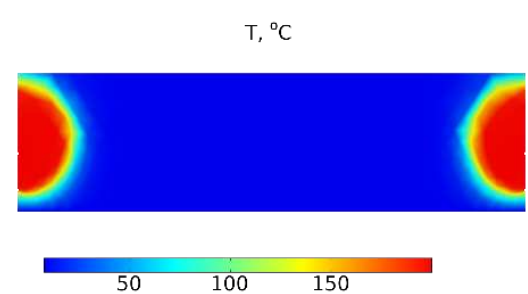

(a)

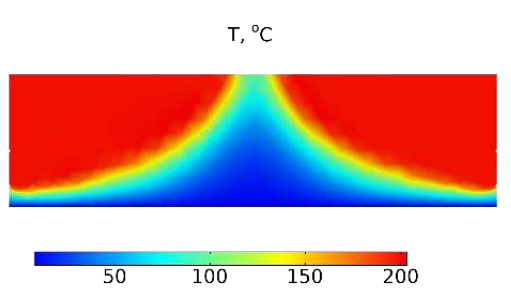

(b)

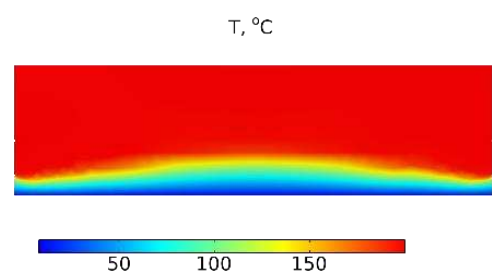

(c)

Figure 1: Temperature distribution: (a) $70^{\text {th }}$ day of SAGD; (b) $800^{\text {th }}$ day of SAGD; (c) $1325^{\text {th }}$ day of SAGD

Figures 2-3 present evolution of porosity and permeability which are functions of volumetric strains shown in figure 4 . It can be seen that steam assisted gravity drainage leads to the increase in porosity and permeability values. Permeability rises to 1.02 compared to the initial values and porosity increases by 0.0014 which is slightly more than 1 percent relative 
to initial value?. It should be emphasized that these results are obtained in thermo-elastic case. More significant increase in porosity and permeability can be obtained by including inelastic strains in the model which doesn't fall under the scope of this work.

Figure 5 shows evolution of temperature field in the presence of two barrier layers. On the initial stage, steam chambers reach barrier layers as it is shown in figure 5 (a) and propagate along it. Left steam chamber reaches the top of the reservoir earlier due to the shorter length of the barrier (fig. 5 (b)). Longer barrier layer above the right steam chamber impedes its upward propagation. Thus, steam chamber close up occurs only to $1300^{\text {th }}$ day of the heating which is 500 days longer compared to the uniform reservoir.

Figure 6 presents temperature distribution for three barrier layers. On the initial stage presented in figure 6 (a) propagation of the steam chamber corresponds to the first case.

n-no

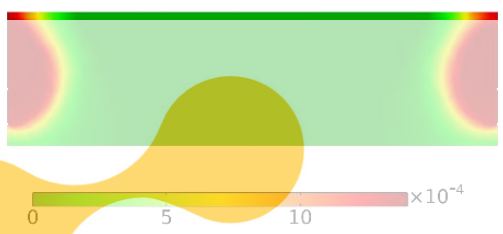

(a)

Figure 2: Difference bet
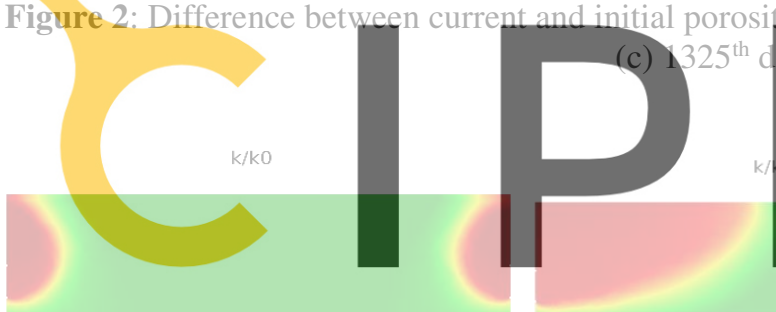

(b)
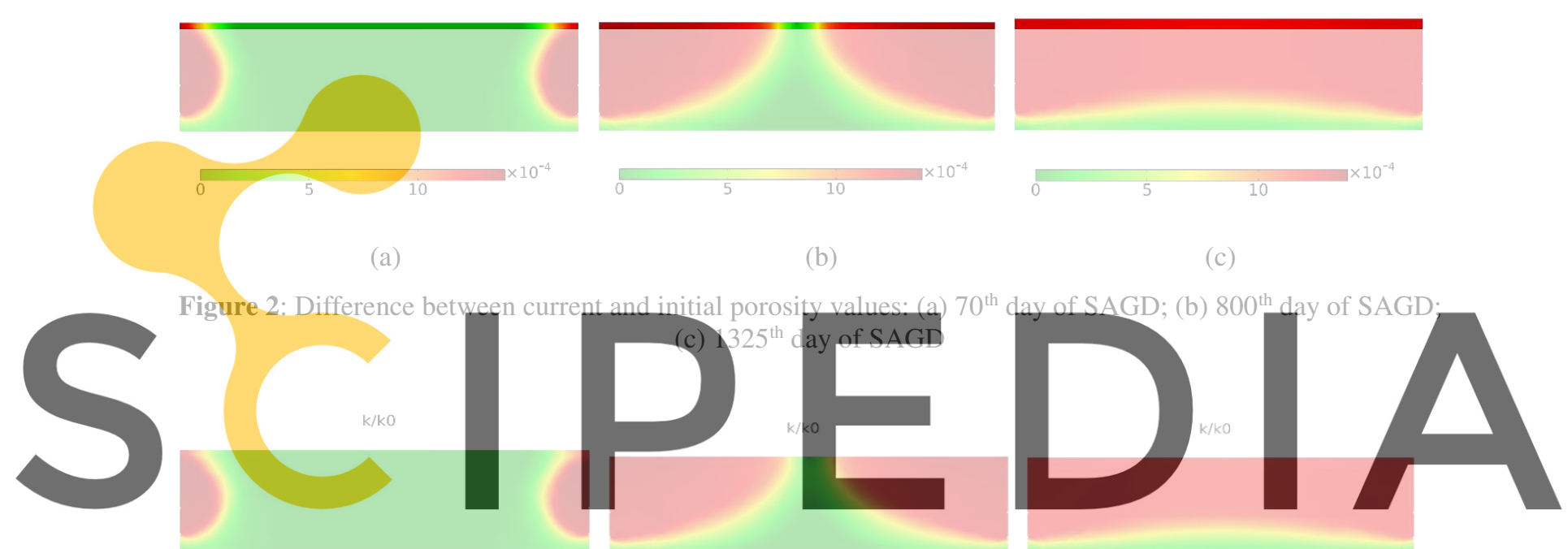

Register for free at https//www.scipedia.com to download the version without the watermark

(a)

(b)

(c)

Figure 3: Ratio of current permeability to initial value: (a) $70^{\text {th }}$ day of SAGD; (b) $800^{\text {th }}$ day of SAGD; (c) $1325^{\text {th }}$ day of SAGD

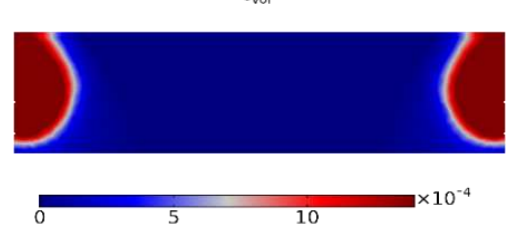

(a)

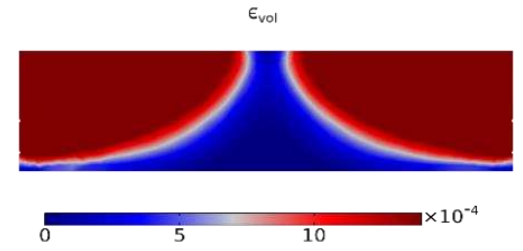

(b)

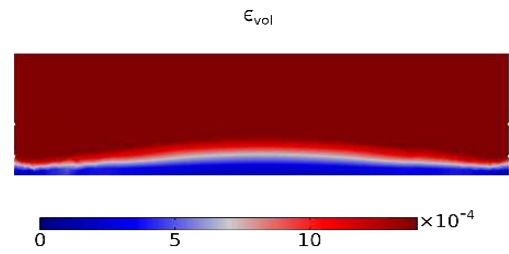

(c)

Figure 4: Distribution of volumetric strain: (a) $70^{\text {th }}$ day of SAGD; (b) $800^{\text {th }}$ day of SAGD; (c) $1325^{\text {th }}$ day of SAGD 
$T, \operatorname{deg} \mathrm{C}$
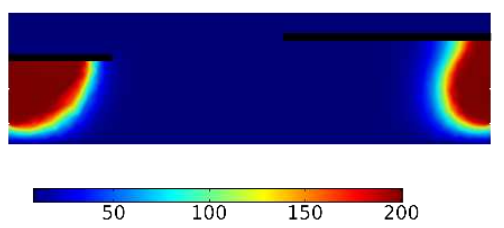

(a)
$\mathrm{T}, \operatorname{deg} \mathrm{C}$
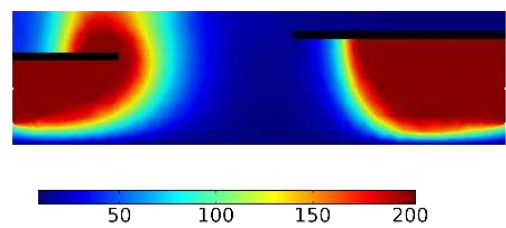

(b)
$\mathrm{T}, \operatorname{deg} \mathrm{C}$

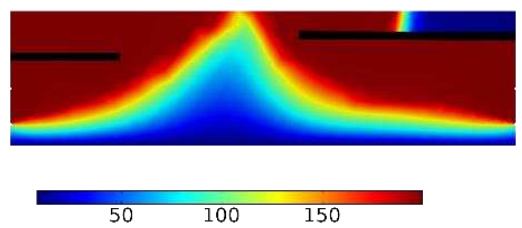

(c)

Figure 5: Temperature distribution for two barrier layers: (a) $160^{\text {th }}$ day of SAGD; (b) $800^{\text {th }}$ day of SAGD; (c) $1300^{\text {th }}$ day of SAGD

However, the presence of the second barrier layer above the first steam chamber impedes upward propagation of it. And to the 1300th day of the heating steam chambers do not close up.
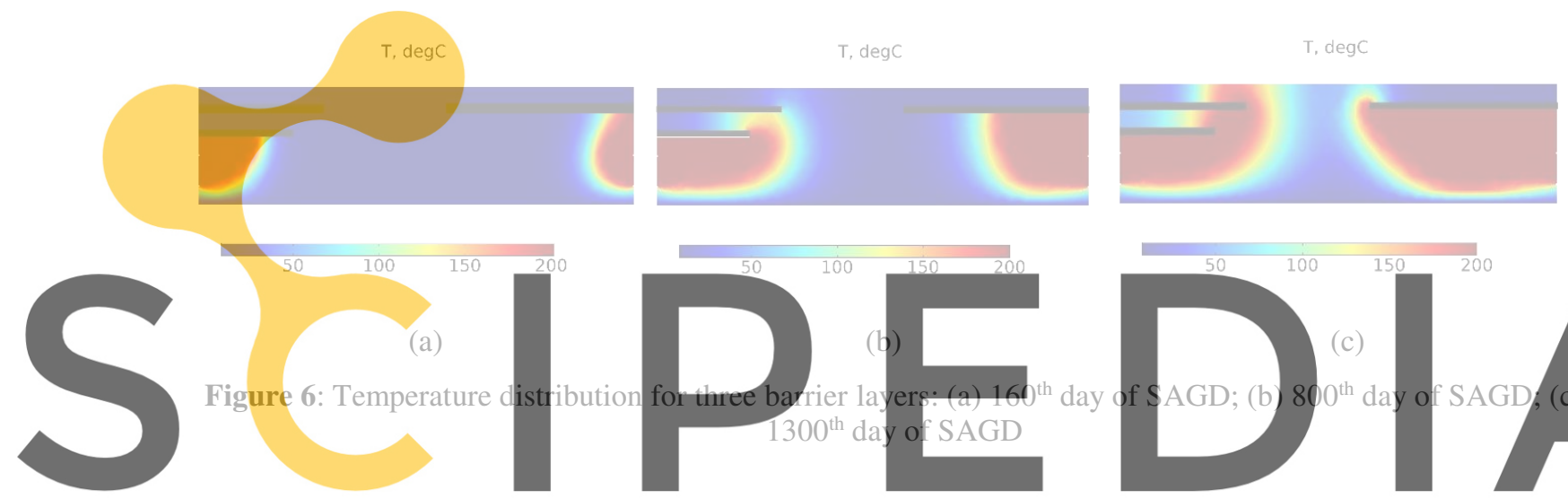

Propagation of the steam chambers for the last configuration is presented in figure 7. In

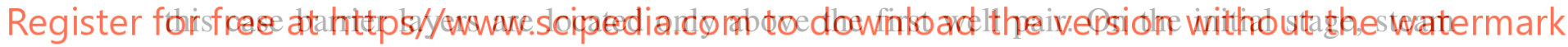
chamber produced by the second well-pair can freely reach the top of the layer while the first steam chamber propagates along the barrier located above it (Fig. 7 (a)). However, barrier layers located near the second steam chamber prevent its spreading and the steam chamber propagates mostly in the upward part of the reservoir (Fig. 7 (b)) outrunning propagation of the first steam chamber which results in its spreading over the whole upper boundary. So, in this case we can observe absolutely different scenario of steam chamber closure (figure 7 (c)).

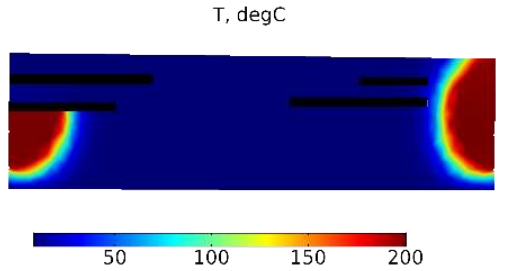

(a)

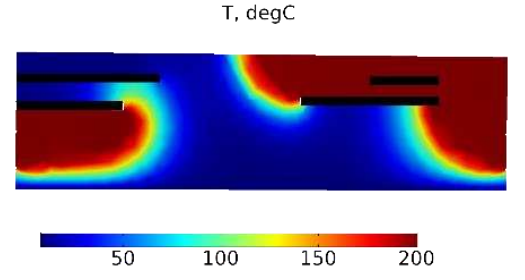

(b)

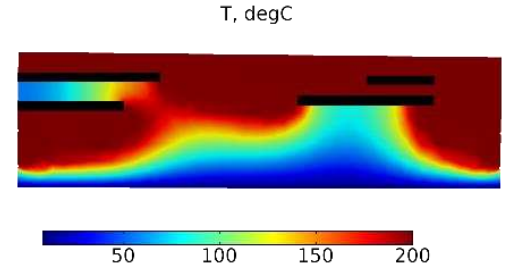

(c)

Figure 7: Temperature distribution for four barrier layers: (a) $90^{\text {th }}$ day of SAGD; (b) $500^{\text {th }}$ day of SAGD; (c) $1365^{\text {th }}$ day of SAGD 
Figure 8 shows oil rates for all considered cases. The first curve corresponds to the homogeneous case. It has three stages: rising stage where steam chambers propagate in the upward direction (up to the $100^{\text {th }}$ day), plateau stage where steam chambers propagate along the top of the layer (from $100^{\text {th }}$ to $800^{\text {th }}$ day) and decreasing stage (after $800^{\text {th }}$ day) corresponding to the steam chamber closure and propagation to the bottom of the layer. The fourth curve corresponding to the last configuration of barriers on the initial stage is similar to the homogeneous case. However, presence of the barrier layer above the first well-pair leads to the decline in oil rate (from $100^{\text {th }}$ day). After $500^{\text {th }}$ day long plateau stage is observed induced by the propagation of the second steam chamber along the top of the layer. Steam chambers corresponding to the first and the second barrier configuration on the initial stage have similar propagation which reflects in the same oil production up to the $400^{\text {th }}$ day (the second and the third curve). After that the oil production rate corresponding to the second configuration starts to deviate from the first case due to the presence of the second barrier layer above the first well pair. After $1100^{\text {th }}$ day the oil production rates of these configurations are almost equal to each other. Therefore, it can be concluded that barrier layers strongly affect the oil production rate.

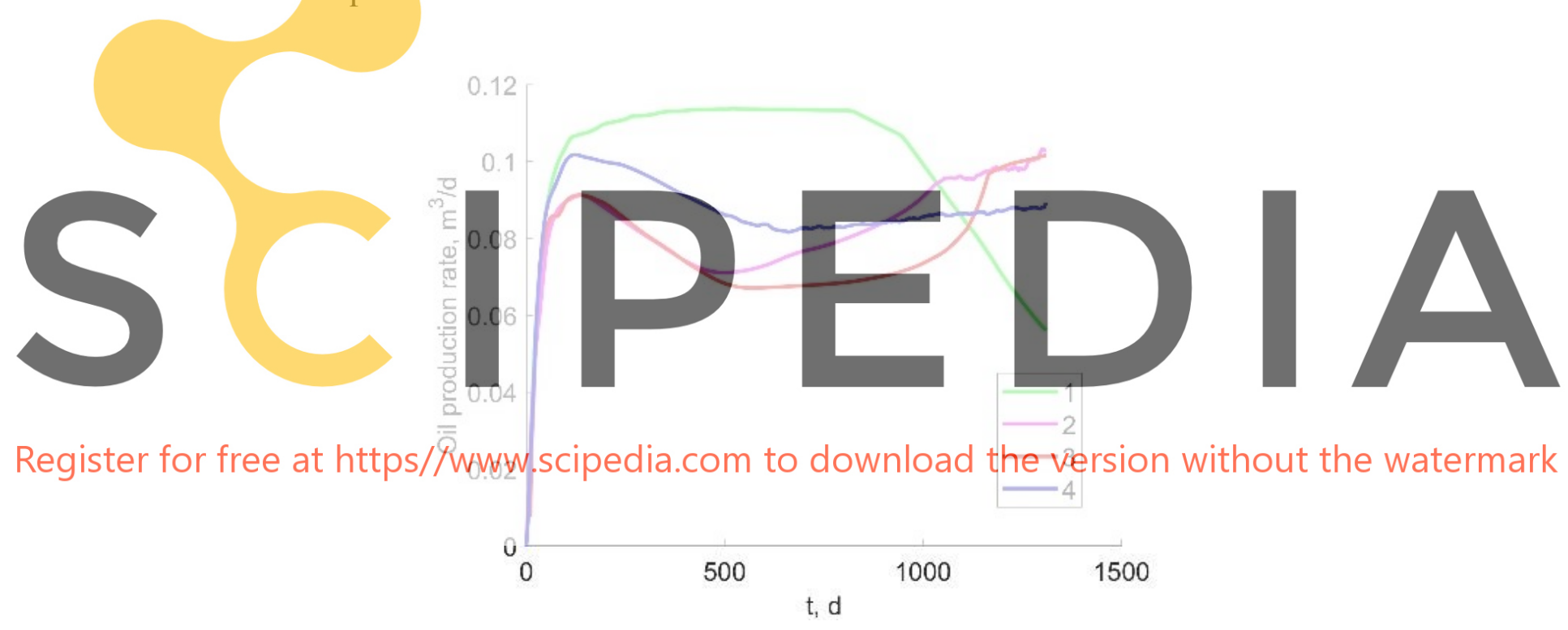

Figure 8: Oil production rate ((1) - homogeneous case; (2) - two barrier layers; (3) - three barrier layers; (4) four barrier layers)

\subsection{Effect of non-uniform steam distribution along the horizontal wellbore}

In order to take into account non-uniformity of steam injection along the horizontal wells we increased thickness of the reservoir up to $70 \mathrm{~m}$. Other geometric characteristics were the same as described in section 3.1 except for the height which was also increased up to $24 \mathrm{~m}$.

Comparison of temperature distribution for uniform (Fig. 9(a)) and non-uniform (Fig. 9(b)) cases has shown that injection non-uniformity strongly affects shape of the steam chamber and slows down its development. For non-uniform case, comparison of steam chambers in the left and right sections normal to the wellbore shows that steam chamber at the left section develops faster than steam chamber at the right section. At 1000th day of SAGD steam 
chambers from the neighboring well-pairs in the right section only begin to close up while steam chambers in the left section go down to the bottom of the reservoir.

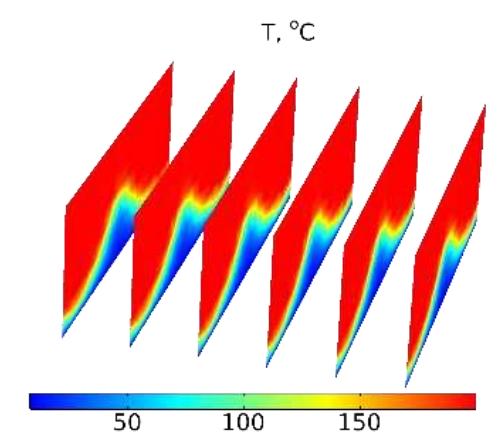

(a)

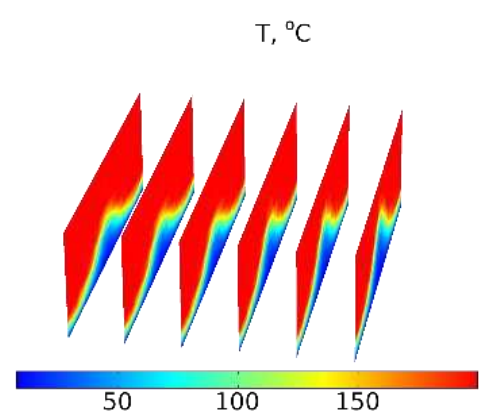

(b)

Figure 9: Temperature distribution in 6 sections normal to the wellbore at 1000 th day of SAGD: (a) uniform case; (b) non-uniform case

Figure 10 presents vertical component of displacament vector. Increase in volumetric strain induced by rise in temperature leads to the surface heave. In case of uniform steam distribution the heave is uniformly distribituted along the surface (Fig. 10 (a)). Results distribution uneven.
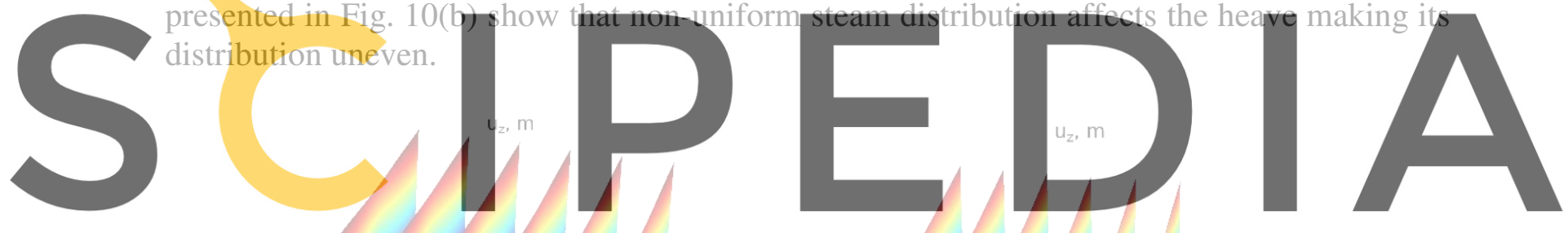

Register for free at https//www.scipedia.com to download the version without the watermark

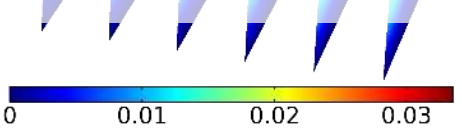

(a)

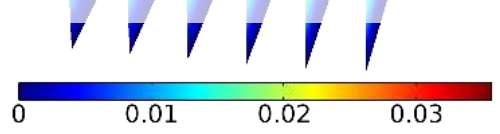

(b)

Figure 10: Vertical displacement in 6 sections normal to the wellbore at $1000^{\text {th }}$ day of SAGD: (a) uniform case; (b) non-uniform case

Figure 11 shows effect of injection non-uniformity on oil production rate. It can be seen that there are three stages of oil production rate for uniform case: increasing stage due to the upward rise of the steam chamber, constant stage induced by the lateral spreading of steam chamber along the top boundary and decreasing stage related to the depleting stage. Nonuniform distribution leads to the decrease in oil production rate. When the steam chamber near the heel reaches the top of the reservoir and begins to spread laterally (the first three sections in Fig. 9(b)), the steam chamber at some distance from the heel can be only at the 
vertical rising stage (the last three sections in Fig. 9(b)) which slows down its development. This effect can significantly affect oil production rate as it has been shown by Fig. 11.

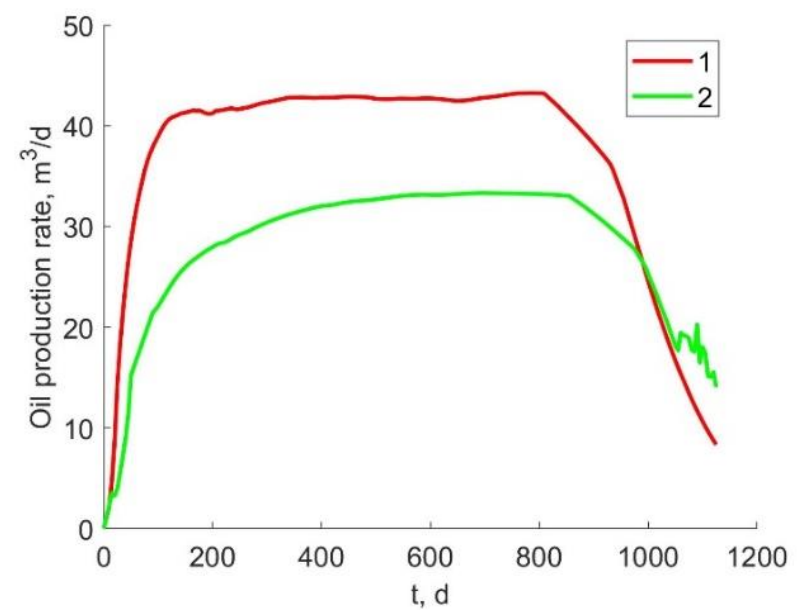

Figure 11: Oil production rate ((1) - uniform case; (2) - non-uniform case)

\section{CONCLUSIONS}

This work proposes a fully coupled thermo-hydro-mechanical model of oil recovery by steam-assisted gravity drainage method. The model describes all stages of steam chamber development, effect of steam condensation, convective heat transfer and evolution of reservoir properties due to thermal strains. Reservoir heating leads to the increase in porosity and permeability inside the steam chamber. Rise of porosity at the final stage of SAGD is slightly more than $1 \%$ and permeability is multiplied by 1.02 at the same time. More significant increase in these values requires accounting for inelastic strains. Results of simulation have shown that accurate prediction of oil production rate requires consideration of the steam chamber non-uniformity induced by technological factors and heterogeneous structure of the reservoir. Presence of the barrier layers in the reservoir impedes steam chamber development and affects its shape. Non-uniformity of the steam chamber along the horizontal wellbore also slows down its development and changes its shape. In this case, description of the steam chamber shape is possible only using three-dimensional model.

\section{ACKNOWLEDGEMENTS}

The work was supported by Russian Science Foundation [grant No. 19-77-30008].

\section{REFERENCES}

[1] Shafiei, A. and Dusseault, M.B. Geomechanics of thermal viscous oil production in sandstones. J. Petrol. Sci. Eng. (2013) 103: 121-139.

[2] Tian, J., Liu, H. and Pang, Z. A study of scaling 3D experiment and analysis on feasibility of SAGD process in high pressure environment. J. Petrol. Sci. Eng. (2017) 150: 238-249.

[3] Butler, R.M., McNab, G.S. and Lo, H.Y. Theoretical studies on the gravity drainage of heavy oil during in-situ steam heating. Can. J. Chem. Eng. (1981) 59: 455-460. 
[4] Reis, J.C. A steam assisted gravity drainage model for tar sands: radial geometry. J. Can. Petrol. Technol. (1993) 32: 43-48.

[5] Zargar, Z. and Farouq Ali, S.M. Analytical modelling of steam chamber rise stage of Steam-Assisted Gravity Drainage (SAGD) process. Fuel (2018) 233: 732-742.

[6] Yin, Y. and Li, Y. FEM Analysis of Fluid-Structure Interaction in Thermal Heavy Oil Recovery Operations. Sustainability (2015) 7: 4035-4048.

[7] Mozaffari, S., Nikookar, M., Ehsani, M. R., Sahranavard, L., Roayaie, E. and Mohammadi, A.H. Numerical modeling of steam injection in heavy oil reservoirs. Fuel (2013) 112: 185-192.

[8] Kostina, A., Zhelnin, M., Plekhov, O. Numerical analysis of a caprock integrity during oil production by steam-assisted gravity drainage method. Frattura ed Integrità Strutturale (2019) 13(49):302-313.

[9] Huang, S., Xia, Y., Xiong, H., Liu, H. and Chen, X. A three-dimensional approach to model steam chamber expansion and production performance of SAGD process// Int. J. Heat Mass Transfer (2018) 127: 29-38.

[10] Huang, S., Yang, L., Xia, Y., Du, M. and Yang, Y. An experimental and numerical study of a steam chamber and production characteristics of SAGD considering multiple barrier layers. J. Petrol. Sci. Eng. (2019) 180: 716-726.

[11] Lee, H., Kharangate, C.R., Mascarenhas, N., Park, I. and Mudawar, I. Experimental and and computational investigation of vertical downflow condensation. Int. J. Heat Mass Transfer (2015) 85: 865-879.

[12] Rahmati, E., Nouri, A., Fattahpour, V. and Trivedi, J. Numerical assessment of the maximum operating pressure for SAGD projects by considering the intrinsic shale anisotropy. J. Petrol. Sci. Eng. (2017) 148: 10-20.

[13] Hu, L., Winterfeld, P. H., Fakcharoenphol, P. and Wu, Y.-S. A novel fully coupled flow and geomechanics model in fractured and porous geothermal reservoirs J. Petrol. Sci. Eng. (2013) 107: 1-11. 